\title{
Predictive capabilities of multiphysics and multiscale models in modeling solidification of steel ingots and DC casting of aluminum
}

\author{
Hervé Combeau $^{1^{*}}$, Miha Založnik ${ }^{1}$, Marie Bedel ${ }^{2}$ \\ ${ }^{1}$ Institut Jean Lamour, CNRS - Université de Lorraine, Dep. SI2M, F-54011 Nancy CEDEX, France \\ ${ }^{2}$ École Nationale Supérieure d'Arts et Métiers, Campus d'Aix-en-Provence, F-13617 Aix-en-Provence, France \\ *Corresponding author: herve.combeau@univ-lorraine.fr
}

\begin{abstract}
Prediction of solidification defects, such as macrosegregation and inhomogeneous microstructures constitutes a key issue for the industry. The development of models of casting processes needs to account for several imbricated length scales and different physical phenomena. For example, the kinetics of the growth of microstructures needs to be coupled with the multiphase flow at the process scale. We introduce such a state-of-the-art model and outline its principles. We present the most recent applications of the model to casting of a heavy steel ingot and to direct chill casting of a large Al alloy sheet ingot. Their ability to help in the understanding of complex phenomena, such as the competition between nucleation and growth of grains in the presence of convection of the liquid and of grain motion is shown, and its predictive capabilities are discussed. Key issues for future developments and research are addressed.
\end{abstract}

Key Words: Multiscale modeling, Solidification processes, Grain structure, Macrosegregation.

\section{INTRODUCTION}

In the metallurgical production chain, the solidification step sets the basic microstructure of the material. The modification of this structure during subsequent processing steps is limited. During solidification several types of defects form, such as heterogeneities of composition: microsegregation at the microstructure scale, macrosegregation at the scale of the product; heterogeneities of structures in terms of grain orientation, size and morphology [1-3]. The reduction of these defects is an important issue for the industry because they impair the final properties of products. Numerical simulation is a valuable tool for progress in this direction. The prediction of macrosegregation and microstructure in solidification processes, such as casting of steel ingots, continuous casting of steel, and direct chill (DC) casting of aluminum alloys, needs in a first step the derivation of a model accounting for nucleation, growth and motion of grains, and for multiphase flow driven by thermal and solutal natural convection. The volume averaging technique is often used to incorporate microscopic phenomena into macroscale models [4-6]. The complexity of this technique lies in the closure relations [7,8] and in the required constitutive relations [9-11]. The second step consists of defining an efficient and robust algorithm that can solve a large number of strongly coupled partial differential equations. We present such a multiscale multiphysics model and its solution procedure in the next section. Then we show the applications of this model to two industrial processes: casting of steel ingots and DC casting of aluminum alloys. We finish by discussing possible issues for the future.

\section{PHYSICAL MODEL AND SOLUTION PROCEDURE}

The multiscale two-phase model SOLID, which we have developed, is presented in detail in refs. [12-15]. The model is based on a volume-averaged Euler-Euler two-phase model that consists of two parts. The macroscopic part describes the transport of momentum, mass, heat, solute mass, grain-population, and population of nucleation sites at the process scale. The microscopic part describes the nucleation and the growth of dendritic grains. This model is a direct extension of the model proposed by Ni and Beckermann [4]. The idea of separation between a microscopic scale and a macroscopic scale is a direct extension of the micro-macro model first introduced by Rappaz [16]. At the macroscopic level, the model accounts for heat and solute transport coupled with two-phase flow driven by thermal and solutal buoyancy. Flow induced by shrinkage, i.e. difference of densities between the solid and the liquid phases, is also accounted for. Depending on the behavior of the solid phase, we consider two flow regimes in the mushy zone. Where the volume fraction of the envelopes of the dendritic grains, $g_{\text {env }}$, is larger than the packing limit $\left(g_{\text {env }}>g_{\text {env,pack }}\right)$ the solid grains are considered to be blocked and the velocity of the solid phase is set to the product velocity (i.e. zero in 
case of static castings, the casting velocity in case of continuous casting). The flow of intergranular liquid through the porous solid matrix is described by a momentum equation including a Darcy term for the drag interactions, with the permeability modeled by the Kozeny-Carman law. In all the simulations presented in this paper, the characteristic length in the Kozeny-Carman law is considered to be constant and uniform. The density of the solid phase is assumed to be constant and for the liquid density the Boussinesq assumption is employed. At grain fractions smaller than the packing limit $\left(g_{\text {env }}<g_{\text {env,pack }}\right)$ the solid phase is considered to be in the form of free floating grains. Their motion is described by a balance of buoyancy, drag and pressure forces acting on the grains. In this way, the solid and liquid have locally different velocities. The interfacial particle drag is considered dependent on the grain size, which produces the tendency that the larger the grains are, the stronger their tendency to settle. Contrarily, smaller grains are more easily entrained by the liquid motion. In order to simulate a columnar zone, the grains in a predefined region close to the mold are imposed to be fixed. The microscopic level is treated locally; within SOLID, this means within each discrete volume element. The apparition of new grains is modeled by a population density of nuclei per unit volume. In case of steel ingots, nuclei are assumed to consist principally of fragments of columnar dendrites. There is therefore no nucleation barrier; equiaxed grains can grow freely on the fragments as soon as the temperature is below the local liquidus temperature. The complexity of this modeling lies in the quantification of a flux of fragments from the columnar zone [3,17-19]. In DC casting of aluminum alloys, nucleation on $\mathrm{TiB}_{2}$ or $\mathrm{TiC}$ inoculant particles is considered. An inoculant particle triggers nucleation at a critical undercooling that is inversely proportional to its size [20]. The size distribution of these particles must therefore be considered. Additionally, the transport of inoculant particles with the flow is described [15,21]. The phase change (solidification and melting) is controlled by solute diffusion in both phases at the grain scale, assuming local thermal equilibrium and thermodynamic equilibrium at the solid-liquid interface. The growth of the dendrite envelopes is described by an LGK-type model of primary tip growth [11]. The macroscopic equations are solved with a finite volume method in two dimensions for a Cartesian or an axisymmetric geometry. The local microscopic growth model is coupled with the macroscopic model via an operatorsplitting integration method [12] that separates the integration of the macroscopic terms, and the growth and nucleation terms. Both operators are integrated with an implicit time stepping scheme. The benefit of this method is an improved stability and computational efficiency of the solution of the strongly coupled equation system.

\section{APPLICATION TO A 65-TON STEEL INGOT}

The simulation of the solidification of a 65 ton steel ingot performed with SOLID is presented in this section as a first illustration of the prediction capabilities of such a model. More details concerning this case can be found in [22]. This ingot was cast by ArcelorMittal Industeel, the steel grade is given in Table I. Metal samples were taken during solidification in the center of the ingot at three different heights: $0.5,1.0$ and 1.5 meters from the top of the ingot. Temperatures were measured in the mold and in the ingot core and sulfur injections were performed to mark the position of the mushy zone.

Table I: Steel grade of the 65-ton ingot cast for this study (solute content in mass \%)

\begin{tabular}{cccccccc}
\hline $\mathrm{C}$ & $\mathrm{S}$ & $\mathrm{P}$ & $\mathrm{Si}$ & $\mathrm{Mn}$ & $\mathrm{Ni}$ & $\mathrm{Cr}$ & $\mathrm{Mo}$ \\
\hline 0.22 & 0.007 & 0.008 & 0.18 & 0.25 & 1.14 & 1.6 & 0.19 \\
\hline
\end{tabular}

The liquidus temperature of this steel grade is $1507{ }^{\circ} \mathrm{C}$. The ingot dimensions were: $3.5 \mathrm{~m}$ height and $1.8 \mathrm{~m}$ diameter (average diameter of the slightly conical shape). The cast iron mold was hot topped with refractory materials along a height of $0.6 \mathrm{~m}$. The steel was bottom poured into the mold with $48{ }^{\circ} \mathrm{C}$ of superheat, the solidification time was around 20 hours. Two simulation results are presented in Fig. 1. The thermo-physical properties, model parameters and the boundary conditions used for these simulations can be found in [22]. In the first simulation the solid phase was assumed to be fixed throughout the ingot. In the second simulation, the motion of equiaxed grains was accounted for. The solid was set to be immobile and fixed to the mold only in a $20 \mathrm{~cm}$ thick layer all across the mold surface. This was done in order to describe the columnar solidification zone. The morphology of the equiaxed grains was approximated as envlar in both simulations. The ingot geometry was modeled as axisymmetric. For the two simulations, the steel grade has been approximated by a binary $\mathrm{Fe}-\mathrm{C}$ system, since carbon has the dominant effect on the solidification interval and on the liquid density variations.

The maps of the final concentration of carbon in the solidified ingot for the two simulation cases and for the experiment are presented in Fig. 1. Fig. 1a shows that with the assumption of a fixed solid phase, the model predicts a mainly positively segregated centerline region, except in the bottom part. A negatively segregated region can be observed in the region surrounding the centerline, extending from the bottom up to the mid-height of the ingot. Another negatively segregated region is located in the hot-top part close to the insulating material. This macrosegregation 
pattern can be explained by considering the liquid flow induced by the thermosolutal convection during solidification. The density of the liquid depends on both its temperature and its concentration. We can estimate the ratio between the solutal and thermal buoyancy as $N=\beta_{C} /\left(m_{\mathrm{L}} \beta_{T}\right)[13,23]$ where $\beta_{T}$ is the thermal expansion coefficient, $\beta_{C}$ the solutal expansion coefficient and $m_{\mathrm{L}}$ the liquidus slope. For the given steel grade, we obtain $N=-1.9$. This means that the buoyancy effect in this steel grade is predominantly solutal and that the solutal effect, caused by the carbon, which is lighter than iron, is counteracting the thermal effect. Across the progressively solidifying mushy zone the liquid density thus decreases with decreasing liquid fraction due to the enrichment of the interdendritic liquid in carbon. This is why the natural convection flow ascends along the sides and descends in the center. Globally, this induces a negative segregation at the bottom of the ingot, where solute-lean liquid from the liquid zone is flowing into regions of lower liquid fraction and replaces solute-rich liquid. According to classical theory [24], a local analysis shows that if the solid phase is fixed, the variation of the concentration with time at a given point in the mushy zone can be approximated by $\mathrm{d} C / \mathrm{d} t \approx \boldsymbol{v}_{1} \cdot \nabla T / m_{\mathrm{L}}$, where $C$ is the local average concentration of the solid-liquid mixture, $t$ is the time, $\boldsymbol{v}_{\mathbf{l}}$ is the liquid velocity vector and $T$ is the temperature. With progressing solidification, the liquid in the core becomes gradually enriched. The enrichment of the core proceeds through the expulsion of carbon-enriched liquid at the top of the core. Therefore we can see a positive segregation zone in the top center at the end (Fig. 1a).

In the case of moving grains, the centerline region is entirely negatively segregated from the bottom up to two thirds of the total height of the ingot. In this case we can distinguish three zones during solidification: (i) the columnar zone (with an imposed thickness along the mold walls), (ii) the slurry equiaxed zone - the part of the ingot core where the equiaxed grains can freely move and (iii) the packed equiaxed zone at the bottom of the ingot core. The flow in the slurry zone is controlled mainly by the moving grains. Because of the lateral heat extraction, the solid fraction in the slurry core is slightly higher at the sides (next to the columnar front). The flow, entrained by the grains, thus descends along the side and ascends in the center. The flow direction is thus reversed compared to the model with a fixed solid phase. The solid grains settle at the bottom of the core in a vertically growing sedimentation layer. We can see that this layer is virtually one-dimensional with respect to macrosegregation (Fig. 1b). As the solute-lean grains settle towards the bottom, the solute-rich liquid gets expulsed upwards. This creates a concentration profile in the ingot that is typical for macrosegregation dominated by grain settling: a negative segregation at the bottom of the ingot, increasing progressively to a strong positive segregation at the top of the ingot. In Fig. 1c, showing to the experiment, it can be seen that the central part of the ingot from the bottom up to $2 / 3$ of its height is composed of globular equiaxed grains and is negatively segregated in carbon. Thus the model results confirm that the macrosegregation in the central part of the ingot is induced by the accumulation of solute-lean moving grains.

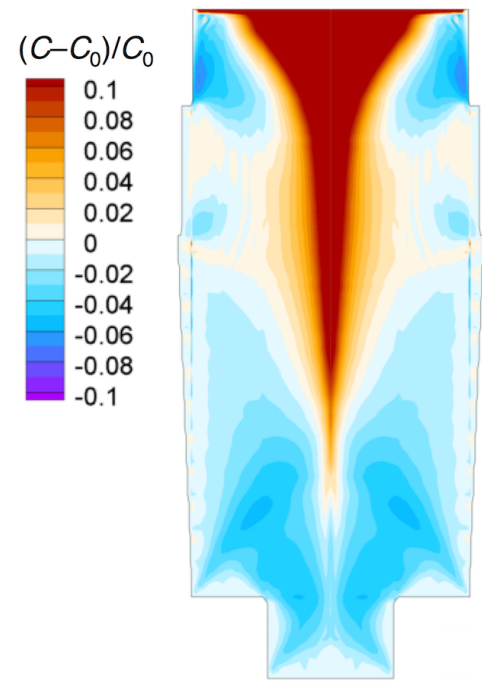

(a)

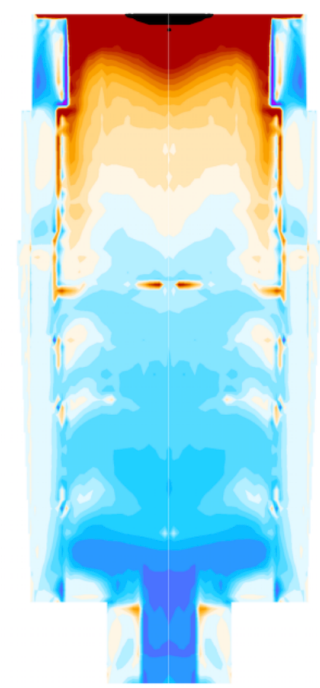

(b)

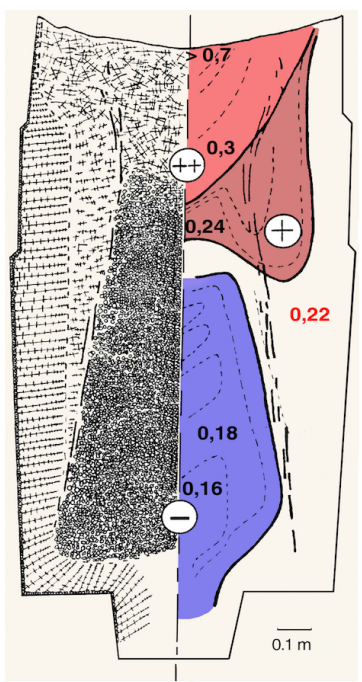

(c)

Figure 1: Macrosegregation in the 65-ton steel ingot. Model prediction with: (a) fixed solid, (b) moving globular grains. (c) Experimental characterization of grain structure and macrosegregation from reference [3].

By sampling of the metal during the solidification, which was performed each hour in the central part of the ingot, we were able to determine two quantities: the average concentration in solute elements at the sampling locations and the position of the coherency front. At the beginning of solidification, samples were taken at three different depths: $1.5 \mathrm{~m}, 1.0 \mathrm{~m}$ and $0.5 \mathrm{~m}$ below the top surface of the ingot. After some time it became impossible to reach the deepest position $(1.5 \mathrm{~m})$ with the probe, because the coherency front had grown higher. After that time the deepest position to which it was possible to immerse the probe was recorded as a measurement of the position of the coherency front. In 
Fig. 2a, the measured evolution of the coherency front is plotted and compared with the evolution of the location of the iso-line of solid fraction of $g_{\mathrm{s}}=0.4$ at the centerline, calculated from the two simulations. This value of $g_{\mathrm{s}}$ corresponds to the packing limit adopted for the simulation with moving grains. Note that for globular grains the grain envelope fraction is identical to the solid fraction. The progression of the solidification in the simulation with a fixed solid is slower than measured in the experiment. On the contrary, the advancement of the coherency front in the simulation with grain motion is faster than the measurement, but closer to the experimental values. These results clearly show that the assumption of the formation of moving equiaxed grains, which results in a faster solidification of the central part of the ingot, is in better agreement with the experiment.

Fig. $2 \mathrm{~b}$ shows the evolution of the average mass fraction in carbon at the centerline at the height of $3 \mathrm{~m}$ from the base of the ingot (depth of $0.5 \mathrm{~m}$ from the top surface and 0.9 in relative height $H / H_{\max }$ ). Good agreement between the experiment and the model results can be observed for both fixed solid and moving grains calculations until the time of $400 \mathrm{~min}$. In the case with moving grains, $400 \mathrm{~min}$ is the time when the packing front reaches the height of $3 \mathrm{~m}$. Due to the sudden accumulation (packing) of grains, the average mass concentration deceases very rapidly. After the packing, the concentration slightly increases again due to the circulation of the interdendritic liquid in the packed region. In the case of a fixed solid phase, the evolution of the average mass concentration in carbon continues to follow the measured evolution. As the upper region of the ingot is composed of dendritic equiaxed grains, it can be expected that the decrease in solute due to the packing of the grains is lower than in the case of globular grains and that the circulation of the liquid in the packed zone is more intense.

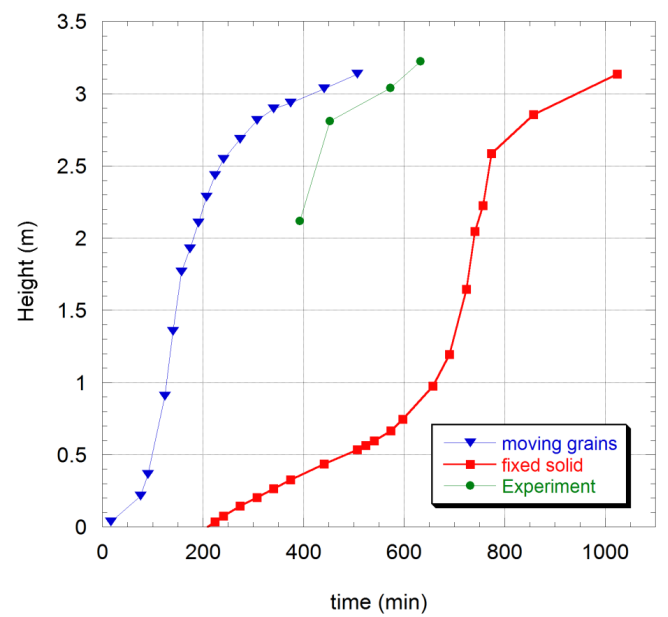

(a)

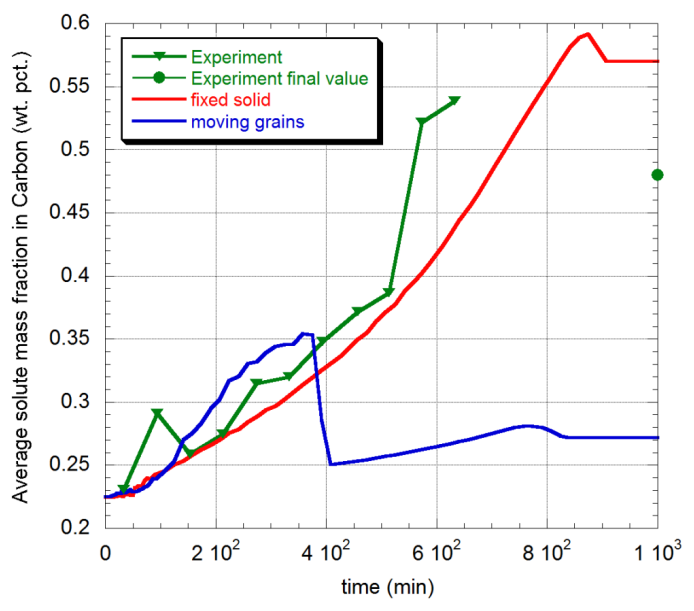

(b)

Figure 2: Confrontation of the experimental and simulation results on the evolution of the solidification of the ingot. (a) Evolution of the height of the solidification front obtained from the sampling experiments and of the iso-solid fraction $g_{\mathrm{s}}=0.4$ at the centerline of the ingot from the simulations. (b) Evolution of the local average mass fraction in carbon at $3 \mathrm{~m}$ from the base (or $0.5 \mathrm{~m}$ below the top surface and 0.9 in relative height $H / H_{\max }$ ) of the ingot.

A classical way to characterize the macrosegregation in a steel ingot is to analyze the final deviation in carbon content from the initial steel grade $\left(\Delta C / C_{0}\right)$ along the ingot axis. This quantity is plotted in Fig. 3 for the experiment and for the two simulations. For relative heights $\left(H / H_{\max }\right)$ lower than 0.7 , the results obtained with moving globular grains are in good agreement with the experimental values, whereas the model with a fixed solid phase predicts a positive segregation instead of a negative. Experimentally we observed that this part of the ingot is negatively segregated and filled with globular grains. Thereby the model that takes into account moving globular equiaxed grains is well suited to describe the formation of the equiaxed zone when the grain morphology is predominantly globular. Above the relative height of 0.7 , the predictions of the model assuming a fixed solid phase start to agree better with the experiment. This better agreement can be explained by the change in morphology of the equiaxed grains observed on the ingot (see Fig. 1c). Above the relative height of 0.7 , the experimental observations show that their morphology is dendritic. As the grains become dendritic, the macrosegregation induced by the packing of the solute-lean grains is of lower intensity than in the case of globular grains. Further, the permeability of a dendritic packed structure is higher since the solid fraction in a dendritic packed layer is lower, which favors the circulation of interdendritic liquid and its impact on positive macrosegregation. As already shown in Fig. 2b, both assumptions (fixed solid phase or moving grains) give a good prediction of the enrichment in solute of the liquid bulk in the upper part of the ingot until $400 \mathrm{~min}$ and even after 400 minutes for the case of the fixed solid phase assumption. So, despite the differences between the phenomena accounted for in the two simulations, the liquid bulk enrichment is well described until the packing of the grains occurs in the upper part. After the packing, which will occur at relatively low solid fraction since the grains are dendritic, the 
circulation of the liquid in fixed solid skeleton is the main mechanism responsible of the macrosegregation development. This is the reason why the model assuming a fixed solid phase gives a good prediction of the segregation in the upper part of the ingot.

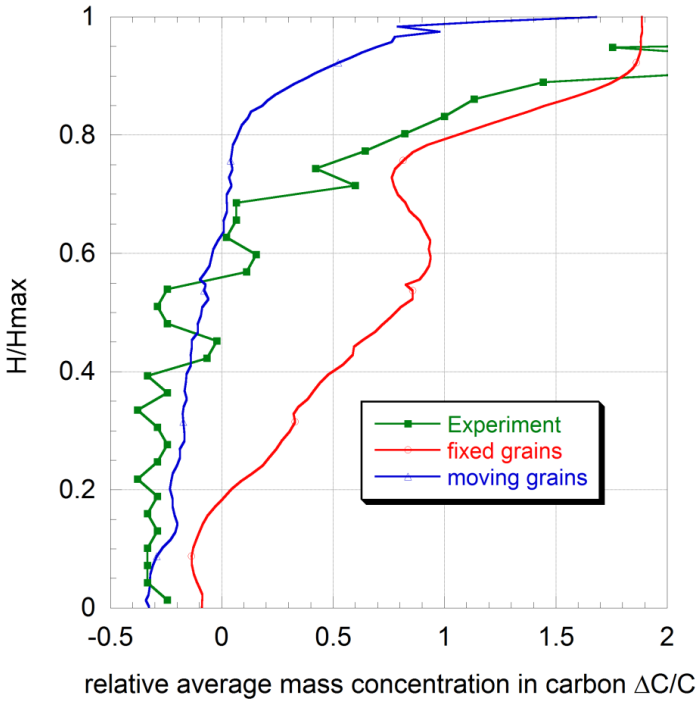

Figure 3: relative deviation of the average mass concentration in carbon $(\Delta \mathrm{C} / \mathrm{C})$ along the centerline measured and calculated with two assumptions: fixed and moving grains.

The comparison between the two simulations shows that the settling of globular equiaxed grains is the predominant cause for the formation of the macrosegregation in the central region of this ingot, while the circulation of the interdendritic liquid plays the predominant role in the formation of the macrosegregation in the top part. These results are encouraging and show that the model is on a good way to being fully predictive. In the next step, a model that includes the description of the globular-dendritic transitions of the grain morphology $[11,25]$ should be applied to this ingot. This will test the ability of the model to predict the grain morphology transitions at the process scale. Some other points also have to be addressed, such as the number of nuclei, which needs to be related to the fragmentation of the dendritic structures, and the possibility for the growth of a columnar zone from the packed equiaxed zone (equiaxed-to-columnar transition) when equiaxed nucleation is exhausted [26].

\section{APPLICATION TO DC CASTING OF ALUMINUM ALLOYS}

DC casting of aluminum alloys is remarkably different from steel ingot casting in terms of the solidification time, the size of the mushy zone, the nucleation, and the size and the morphology of the microstructures. The formation of the microstructure and the macrosegregation in DC casting of aluminum alloys is also characterized by an intricate interplay of the melt flow, the motion of free-floating equiaxed grains in the slurry zone and the flow of intergranular liquid through the porous solid network in the packed zone (Fig. 4a). DC casting is a semi-continuous process and the mushy zone is most of the time in a steady state. A particular feature of this process is the control of the microstructure size by addition of Al-Ti-B or Al-Ti-C grain refiners. $\mathrm{TiB}_{2}$ or $\mathrm{TiC}$ inoculant particles, which act as nucleation sites for equiaxed grains, are added into the molten metal and are transported by the melt flow. According to the athermal nucleation theory [27], an inoculant particle becomes active and initiates the growth of a grain at the critical undercooling that is inversely proportional to the size of the particle. The size distribution of the inoculant particles follows an exponential distribution density function corresponding to a distribution of activation undercooling (Fig. 4b). Due to the substantial spread of the particle sizes, the nucleation occurs across a certain temperature range. A classical analysis of the ongoing nucleation events and of the concurrent growth of already nucleated grains during cooling shows that the latent heat release from the growing grains at some point stifles further nucleation [27]. We call this phenomenon the nucleation-growth competition (NGC). A purely local analysis of the NGC indicates that the number of nucleated grains is then simply determined by the maximum undercooling reached during the NGC. In casting processes a local analysis of the NGC is not sufficient anymore. The local population of the inoculant particles and of the nucleated equiaxed grains is continuously altered due to convective transport at the process scale. The modeling of the grain formation therefore requires a detailed description of the coupling between nucleation and growth kinetics, and the macroscopic transport phenomena. With a strongly coupled modeling of all these phenomena we have succeeded for the first time to predict the coupling of the formation of the grain structure and of the macrosegregation in direct-chill castings $[14,21,28]$. 
We used the model to simulate the solidification of a 5182-alloy industrial scale sheet ingot. The ingot of 510 $\mathrm{mm}$ thickness and $1897 \mathrm{~mm}$ width was cast at a speed of $1 \mathrm{~mm} / \mathrm{s}$, partly with $1 \mathrm{~kg} / \mathrm{t}$ of Al-3Ti-1B grain refiner and partly without grain refiner. These experiments were conducted in the framework of the BRITE EURAM project EMPACT [29-31]. Profiles of average grain diameter across the ingot thickness were obtained by image analysis of optical microscopy samples [32]. The thermophysical properties, process parameters and boundary conditions used in the simulations are given in [14,28]. The 5182 alloy was modeled by a binary Al-4.06 wt $\% \mathrm{Mg}$ system, since magnesium has the dominant effect on the solidification interval and on the liquid density variations. The inoculant particle size distribution in the grain-refined part of the ingot was approximated by the distribution of $\mathrm{TiB}_{2}$ particles measured for an Al-5Ti-1B grain refiner [30] and corresponding to the same addition level as used in the experiments. The non-grain-refined part was modeled by the same distribution reduced by a factor of 8 . This is a rough estimate that corresponds to the observed increase of the average grain size by a factor of 2 (Fig. 5a). The growth of the equiaxed grains was modeled by a three-phase volume-averaged model that describes dendritic grains by distinguishing their envelope and the solid inside the envelope. The model [14] is the same as in ref. [11], except for a modified correlation for the liquid diffusion length at the envelope [33]. The predicted grain morphologies were globular. In the simulations with moving grains the equiaxed grains were supposed to pack at a grain volume fraction of 0.3 . In addition to the refined and non-refined case, a hypothetical case without motion of equiaxed grains and of inoculant particles was simulated. A comparison with this case shows the importance of accounting for grain and inoculant motion in the modeling of microstructure in DC casting.

Fig. 5a shows the predicted grain size across the ingot thickness. The local equivalent grain diameter, $d_{\mathrm{eq}}$, was calculated from the local volume density of the grain population, $N_{\mathrm{V}}: d_{\mathrm{eq}}=(6 / \pi)^{1 / 3} N_{\mathrm{V}}{ }^{-1 / 3}$. The simulations with moving grains and inoculant particles correctly predict the order of magnitude of the grain size in both the grain-refined and the non grain-refined case. All details of the grain size variations are not captured however. Note that no parameters were fitted in the grain-refined case. In the non grain-refined case the nuclei population was reduced by the same factor as the population of grains observed experimentally in the cast structure. Yet such an estimate is not enough to ensure a correct prediction. Because of the nonlinearity of the NGC, the grain density of the cast structure cannot be inferred a priori. A physically correct description of the coupled phenomena is required.

It is striking to see that the simulation without grain motion entirely fails to reproduce the grain size and its variation across the ingot thickness. In absence of grain motion, the variation of the cooling rate across the thickness is the only mechanism that controls the NGC and thus the grain size. This mechanism alone obviously fails to capture the essential physics. This indicates that the motion of grains and of inoculant particles is decisive in the formation of microstructure variations in the DC cast ingot. In absence of motion of equiaxed grains and inoculant particles, the grain size is determined by the cooling rate. The higher the cooling rate, the higher is the maximum undercooling attained due to the NGC. The number of nucleated grains is in this case directly linked to the maximum undercooling by the nuclei size distribution. In a DC casting the cooling rate and thus the maximum reached undercooling are the largest at the ingot surface and decrease towards the centerline. This can be seen in Fig. $5 \mathrm{~b}$ that shows the profile of the maximum undercooling across the ingot thickness. Due to a decrease of the maximum undercooling, the grain size increases from the surface to the center [15].

The simulation with moving equaxed grains and inoculant particles shows an entirely different picture. The local populations of inoculant particles and of growing grains are not only a result of the competition between nucleation and growth, but are also altered by the convective transport. In this way the micro-scale coupling between the nucleation and the growth of the equiaxed grains is strongly influenced by the flow at the process scale. It is therefore important to understand the flow structure. Below the entry of the melt from the inlet into the mold the flow is mainly governed by natural convection. The natural convection is a consequence of gradients of temperature, solute concentration and solid fraction in the liquid and the mushy zone. Although the enrichment of the liquid with magnesium causes a decrease of the liquid density as solidification progresses, the driving forces due to temperature gradients in the liquid zone and due to solid-fraction gradients in the slurry zone prevail. Their cooperation induces a flow loop that runs as a fast current downward along the solidification front (mushy zone) to the centerline and then slowly ascends in the center. The freefloating equiaxed grains are entrained by the flow and basically follow this trajectory. They also tend to settle towards the bottom of the mushy zone because the solid grains have a higher density than the liquid.

With such a flow structure the slurry zone close to the ingot surface is continuously supplied with "fresh" melt from the mold inlet, carrying the nominal population density and distribution of inoculant particles. The undercooled area just below the liquidus isotherm can be imagined as a control volume in which a part of the incoming particles nucleates and forms grains. The nucleated grains are continuously drained off with the downward oriented flow current. The nucleation rate in the control volume depends on the local undercooling (the part of the particle distribution that is activated) and on the flow rate of particles passing through the volume. A higher flow velocity will not only supply the inoculant particles at a higher rate, but will also carry away the nucleated grains faster. Through the NCR a faster evacuation of growing grains will further increase the undercooling and promote nucleation. Incidentally, the cooling rate in this part of the mushy zone is also rather high, further increasing the efficiency of nucleation. The grains that 
nucleate here are then partly carried to the bottom to the packed zone and partly spread out throughout the slurry zone. In Fig. 6 we can see that all the melt that enters the mushy zone first passes through the nucleation area. The map of undercooling in Fig. 6 indicates that the highest undercooling in the whole mushy zone is reached in the same area. This means that all sufficiently large inoculant particles that enter the mushy zone are activated in the nucleation area. Only smaller particles that require large undercoolings remain. They cannot be activated later on their trajectory because the undercooling in the rest of the slurry zone is much lower. Nucleation is therefore restricted to the nucleation area in the top outer part of the mushy zone marked in Fig. 6. This area is the generator of equiaxed grains for the whole mushy zone. This is additionally supported by the profile of maximum undercooling across the ingot thickness, shown in Fig. 5b. Only undercoolings larger than $0.1{ }^{\circ} \mathrm{C}$ trigger nucleation on the inoculant particles. We can see that sufficient undercoolings are reached only at the outer part of the ingot thickness, at $x>130 \mathrm{~mm}$. We can also note that the undercoolings are much higher than in the simulation without grain motion, thus activating a larger portion of the nuclei particle distribution. In the non grain-refined ingot the reached maximum undercoolings are almost twice as high as in the grain-refined ingot (Fig. 5b). Due to the smaller population density of growing grains in this case, the NGC results in higher undercooling and a much larger portion of the inoculant particle size distribution is activated in the nucleation process.

The undercooling map of the grain-refined ingot in Fig. 6 shows the different areas of grain nucleation and growth. An undercooling higher than $0.1 \mathrm{~K}$ indicates a nucleation area. An undercooling higher than $0 \mathrm{~K}$ indicates an area of grain growth. Higher undercooling results in faster growth. A negative undercooling means superheat and indicates dissolution of the solid grains. The model thus reveals four regions of grain nucleation and growth in the slurry zone: (i) a very limited nucleation region at the packing front close to the entry point of the melt flow, (ii) a fast solidification region next to the inclined packing front, (iii) a stagnation region in the core of the slurry zone, and (iv) a remelting region close to the liquidus front. The model results also indicate the disparate origin and evolution of the grains found in different parts of the cast structure across the ingot thickness. The grains in the outer parts of the ingot undergo a short period of fast growth before packing at the inclined part of the packing front. The grains in the center are a mix of two types of grains with different histories. The fast-growing grains packed immediately after settling from the descending flow current, and the slow-growing grains settled to the bottom only after a prolonged trajectory in the stagnant growth region. The two types of grains form a duplex structure, observed in many experiments [29,34-40].

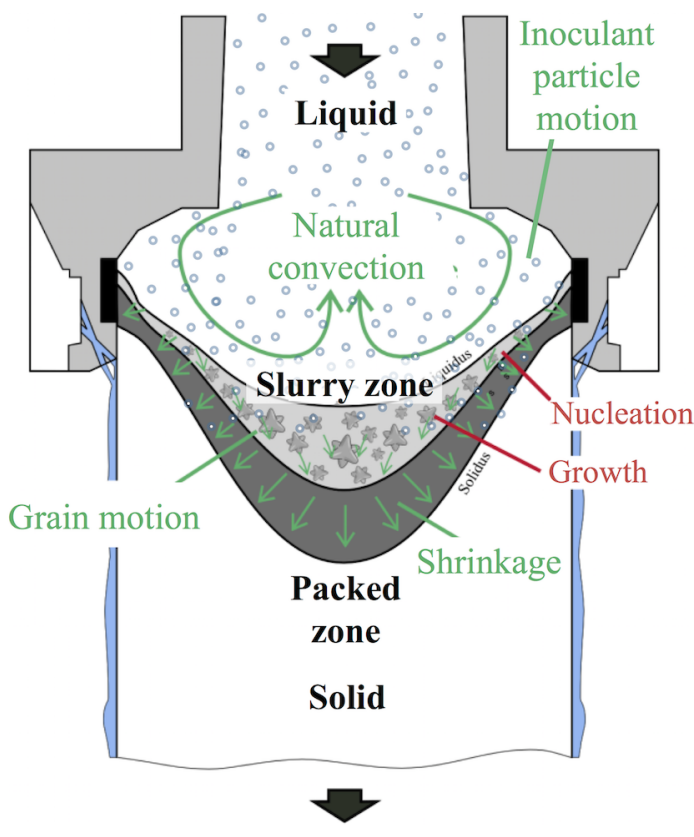

(a)

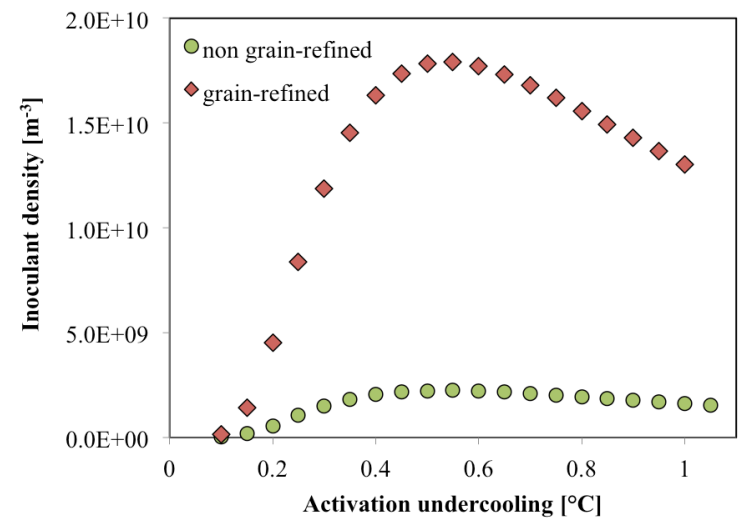

(b)

Figure 4: Phenomena involved in the formation of the microstructure. (a) Transport phenomena involved in the formation of the microstructure and coupling with microscopic phenomena. (b) Discretized nucleation law deduced from the inoculant particle size distribution. Inoculant classes corresponding to $1 \mathrm{~kg} / \mathrm{t}$ of $\mathrm{Al}-5 \mathrm{Ti}-1 \mathrm{~B}$ refiner (red diamonds) and to $0.125 \mathrm{~kg} / \mathrm{t}$ of Al-5Ti-1B refiner (green circles) [30]. 


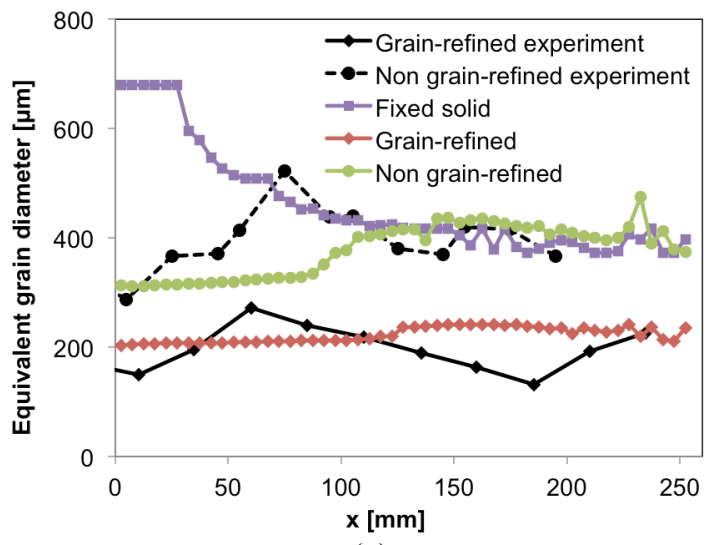

(a)

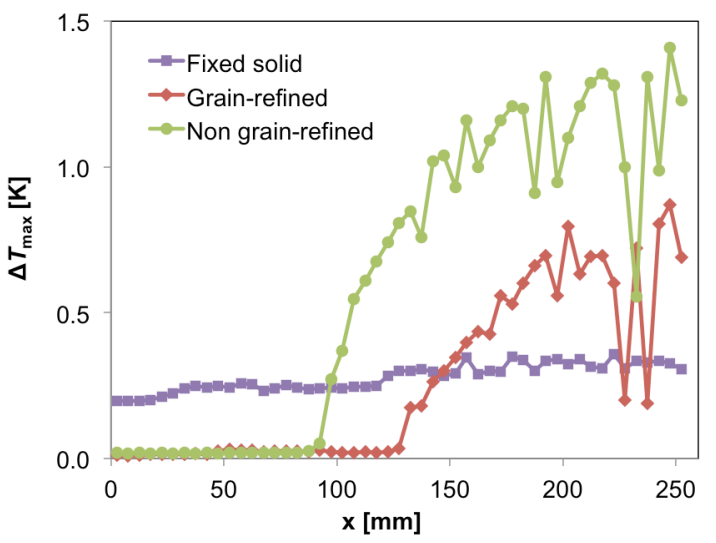

(b)

Figure 5: Predictions of the grain size profile across the ingot thickness. (a) Profiles of equivalent grain diameter. (b) Profiles of maximum undercooling as an indicator of the activation of inoculant particles.

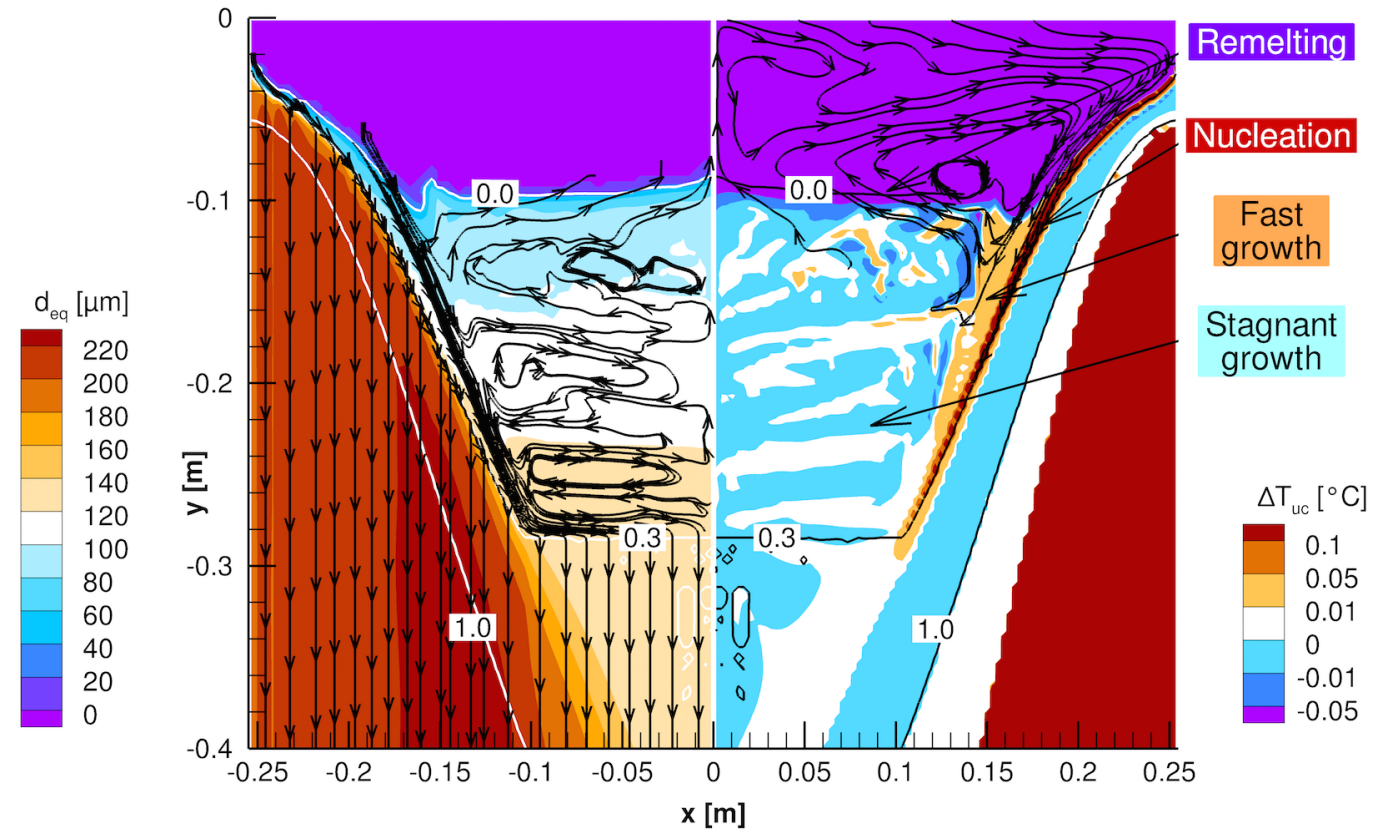

Figure 6: Nucleation, growth, and coalescence of free-floating grains. Left: grain size field and solid velocity streamlines in the mushy zone (an approximation of the grain trajectories due to a qualitatively steady state). Right: undercooling $\left(0.1^{\circ} \mathrm{C}\right.$ is the activation undercooling for the largest inoculant particles) and liquid velocity streamlines in the liquid zone. Solid fraction contours are shown to indicate the liquidus $\left(g_{\mathrm{s}}=0\right)$, the packing $\left(g_{\mathrm{s}}=0.3\right)$, and the solidus $\left(g_{\mathrm{s}}=1\right)$ fronts.

\section{CONCLUSIONS}

We have briefly described the principles of a solidification model predicting the macrosegregation and the microstructure in metal castings and have shown its capabilities through two industrial applications. In the case of the application of the model to a heavy steel ingot it has been shown that the model, when accounting for grain motion, is able to describe the structure formation and the macrosegregation in the central part of the ingot. However as in this simulation the morphology of the grains has been fixed to globular grains, the macrosegregation in the upper part of the ingot is less intense than observed experimentally. At the contrary the simulation assuming the solid phase as fixed gives a wrong prediction in the central part, but a good prediction in the upper part. The equiaxed morphology of the grains in the upper part is the reason for this better prediction. The macrosegregation in the upper part of the ingot is mainly dominated by the circulation of the interdendritic liquid, whereas in the center and the bottom part it is caused by the settling and accumulation of globular grains. 
In the case of the application of the model to DC casting of aluminum alloys we were able to study for the first time the coupling between nucleation and growth of the grains in presence of liquid convection and the transport of grains and inoculant particles at the macroscopic scale. We show that grain motion is a key phenomenon for the understanding of the final microstructure size. A correct modeling of these phenomena enables us to predict an average final grain size close to the experimental observations. However, the grain size evolution across the ingot thickness is not accurately predicted. The regions of nuclei activation and of grain growth in the mushy zone of the ingot have been identified. Notably, it has been shown that the nucleation region is limited to a very small area located at the interface between the slurry and the packed zone between the skin and the mid-thickness

Although these results are promising, some further efforts in different directions are needed. The understanding of phenomena such as dendrite fragmentation, grain packing, nucleation and growth of grains in presence of convection should be improved. This will require dedicated experiments and models at a scale smaller than that of the product.

\section{ACKNOWLEDGEMENT}

The authors are grateful to the French State for the support through the program "Investment in the future" operated by the National Research Agency (ANR) and referenced by ANR-11 LABX-0008-01 (LabEx DAMAS).

\section{REFERENCES}

1. J. A. Dantzig and M. Rappaz, Solidification, 1st ed. (EPFL Press, Lausanne, 2009).

2. C. Beckermann, Int. Mater. Rev. 47, 243 (2002).

3. G. Lesoult, Mater. Sci. Eng. A 414, 19 (2005).

4. J. Ni and C. Beckermann, Metall. Trans. B 22B, 349 (1991).

5. D. R. Poirier, P. J. Nandapurkar, and S. Ganesan, Metall. Trans. B 22, 889 (1991).

6. P. Bousquet-Melou, B. Goyeau, M. Quintard, F. Fichot, and D. Gobin, Int. J. Heat Mass Transf. 45, 3651 (2002).

7. S. Whitaker, Transp. Porous Media 25, 27 (1996).

8. B. Goyeau, T. Benihaddadene, D. Gobin, and M. Quintard, Metall. Mater. Trans. B 30, 613 (1999).

9. C. Y. Wang, S. Ahuja, C. Beckermann, and H. C. De Groh III, Metall. Mater. Trans. B 26, 111 (1995).

10. C.-A. Gandin, G. Guillemot, B. Appolaire, and N. T. Niane, Mater. Sci. Eng. A 342, 44 (2003).

11. B. Appolaire, H. Combeau, and G. Lesoult, Mater. Sci. Eng. A 487, 33 (2008).

12. M. Založnik and H. Combeau, Comput. Mater. Sci. 48, 1 (2010).

13. H. Combeau, M. Založnik, S. Hans, and P. E. Richy, Metall. Mater. Trans. B 40, 289 (2009).

14. M. Bedel, Étude de la formation des structures de solidification et des macroségrégations en coulée semicontinue d'aluminium, PhD thesis, Université de Lorraine, Nancy, France, 2014.

15. M. Bedel, K. O. Tveito, M. Založnik, H. Combeau, and M. M’Hamdi, Comput. Mater. Sci. 102, 95 (2015).

16. M. Rappaz, Int. Mater. Rev. 34, 93 (1989).

17. G. Lesoult, H. Combeau, and M. Moukassi, J. Phys. IV 3(C7), 813 (1993).

18. E. Liotti, A. Lui, R. Vincent, S. Kumar, Z. Guo, T. Connolley, I. P. Dolbnya, M. Hart, L. Arnberg, R. H. Mathiesen, and P. S. Grant, Acta Mater. 70, 228 (2014).

19. H. Neumann-Heyme, K. Eckert, and C. Beckermann, Phys. Rev. E 92, 1 (2015).

20. T. E. Quested and A. L. Greer, Acta Mater. 53, 2683 (2005).

21. M. Založnik, A. Kumar, H. Combeau, M. Bedel, P. Jarry, and E. Waz, Adv. Eng. Mater. 13, 570 (2011).

22. H. Combeau, A. Kumar, M. Založnik, I. Poitrault, G. Lacagne, A. Gingell, T. Mazet, and G. Lesoult, in Int. Conf. Ingot Casting, Rolling, and Forging (Aachen, Germany, 2012), pp. 27-36.

23. J. P. Gu and C. Beckermann, Metall. Mater. Trans. A 30, 1357 (1999).

24. M. C. Flemings and G. E. Nereo, Trans. Metall. Soc. AIME 239, 1449 (1967).

25. M. Založnik and H. Combeau, in Modeling of Casting Welding and Advanced Solidification Processes XII, eds. S. L. Cockroft and D. M. Maijer (TMS, Warrendale, 2009), pp. 165-172.

26. N. Leriche, H. Combeau, C.-A. Gandin, and M. Založnik, IOP Conf. Ser. Mater. Sci. Eng. 84, 012087 (2015).

27. A. L. Greer, A. M. Bunn, A. Tronche, P. V Evans, and D. J. Bristow, Acta Mater. 48, 2823 (2000).

28. M. Bedel, L. Heyvaert, M. Založnik, H. Combeau, D. Daloz, and G. Lesoult, IOP Conf. Ser. Mater. Sci. Eng. 84, 012100 (2015).

29. A. Joly, G.-U. Grün, D. Daloz, H. Combeau, and G. Lesoult, Mater. Sci. Forum 329-330, 111 (2000).

30. A. Tronche, Investigation and Modelling of Inoculation of Aluminium by $\mathrm{TiC}, \mathrm{PhD}$ thesis, University of Cambridge, 2000.

31. G. Lesoult, V. Albert, B. Appolaire, H. Combeau, D. Daloz, A. Joly, C. Stomp, G.-U. Grün, and P. Jarry, Sci. 
Technol. Adv. Mater. 2, 285 (2001).

32. D. Daloz, H. Combeau, A. Joly, G. Lesoult, G.-U. Grün, P. Jarry, and B. Commet, in Matériaux 2002, de la conception à la mise en oeuvre (Tours, France, 2002).

33. K. O. Tveito, M. Bedel, M. Založnik, H. Combeau, and M. M'Hamdi, IOP Conf. Ser. Mater. Sci. Eng. 27, 012040 (2012)

34. H. Yu and D. A. Granger, in Aluminium Alloys: Their Physical and Mechanical Properties (EMAS, Sheffield, UK, 1986), pp. 17-29.

35. T. L. Finn, M. G. Chu, and W. D. Bennon, in Micro/Macro Scale Phenomena in Solidification, eds. C. Beckermann, L. A. Bertram, S. J. Pien, and R. E. Smelser (ASME, New York, 1992), pp. 17-24.

36. D. G. Eskin, Physical Metallurgy of Direct Chill Casting of Aluminum Alloys (CRC Press, Boca Raton, FL, 2008).

37. D. G. Eskin, R. Nadella, and L. Katgerman, Acta Mater. 56, 1358 (2008).

38. R. Nadella, D. G. Eskin, and L. Katgerman, Metall. Mater. Trans. A 39, 450 (2008).

39. R. Nadella, D. G. Eskin, Q. Du, and L. Katgerman, Prog. Mater. Sci. 53, 421 (2008).

40. D. G. Eskin, A. Jafari, and L. Katgerman, Mater. Sci. Technol. 27, 890 (2011). 